\title{
Effect of Amniotic Fluid Stem Cells and Amniotic Fluid Cells on the Wound Healing Process in a White Rat Model
}

\author{
Jung Dug Yang ${ }^{1}$, Dong Sik Choi ${ }^{1}$, Young Kyoo Cho ${ }^{1}$, Taek Kyun Kim${ }^{1}$, Jeong Woo Lee ${ }^{1}$, \\ Kang Young Choi ${ }^{1}$, Ho Yun Chung ${ }^{1}$, Byung Chae $\mathrm{Cho}^{1}$, Jin Suk Byun ${ }^{2}$ \\ ${ }^{1}$ Department of Plastic and Reconstructive Surgery, Kyungpook National University School of Medicine, Daegu; ${ }^{2}$ BS Aesthetic Clinic, Daegu, \\ Korea
}

Background Amniotic-fluid-derived stem cells and amniocytes have recently been determined to have wound healing effects, but their mechanism is not yet clearly understood. In this study, the effects of amniotic fluid stem cells and amniocytes on wound healing were investigated through animal experiments.

Methods On the back of Sprague-Dawley rats, four circular full-thickness skin wounds $2 \mathrm{~cm}$ in diameter were created. The wounds were classified into the following four types: a control group using Tegaderm disc wound dressings and experimental groups using collagen discs, amniotic fluid stem cell discs, and amniocyte discs. The wounds were assessed through macroscopic histological examination and immunohistochemistry over a period of time.

Results The amniotic fluid stem cell and amniocyte groups showed higher wound healing rates compared with the control group; histologically, the inflammatory cell invasion disappeared more quickly in these groups, and there was more significant angiogenesis. In particular, these groups had significant promotion of epithelial cell reproduction, collagen fiber formation, and angiogenesis during the initial 10 days of the wound healing process. The potency of transforming growth factor- $\beta$ and fibronectin in the experimental group was much greater than that in the control group in the early stage of the wound healing process. In later stages, however, no significant difference was observed.

Conclusions The amniotic fluid stem cells and amniocytes were confirmed to have accelerated the inflammatory stage to contribute to an enhanced cure rate and shortened wound healing period. Therefore, they hold promise as wound treatment agents.

Keywords Amniotic fluid / Stem cells / Wound healing
Correspondence: Jung Dug Yang Department of Plastic and Reconstructive Surgery, Kyungpook National University School of Medicine, 130 Dongdeok-ro, Jung-gu, Daegu 700-421, Korea Tel: +82-53-420-5688 Fax: +82-53-425-3879 E-mail: ganjiborder@naver.com

This article contains supplemental Fig. S1.

No potential conflict of interest relevant to this article was reported.

Received: 22 Apr 2013 • Revised: 25 Jul 2013 • Accepted: 27 Jul 2013

pISSN: 2234-6163 • elSSN: 2234-6171 • http://dx.doi.org/10.5999/aps.2013.40.5.496• Arch Plast Surg 2013;40:496-504

\section{INTRODUCTION}

Recent studies show that amniotic fluid contains a considerable quantity of multipotent mesenchymal, hematopoietic, neural, epithelial, and endothelial stem cells [1]. These amniotic fluid stem cells (AFSCs) are pluripotent and able to differentiate into various kinds of tissue, which may be useful for clinical applications. Some researchers have found that amniotic fluid is also

Copyright $(92013$ The Korean Society of Plastic and Reconstructive Surgeons

This is an Open Access article distributed under the terms of the Creative Commons Attribution Non-Commercial License (http://creativecommons.org/

licenses/by-nc/3.0/) which permits unrestricted non-commercial use, distribution, and reproduction in any medium, provided the original work is properly cited

www.e-aps.org 
a plentiful source of non-embryonic stem cells. A potential benefit of using amniotic stem cells over those obtained from embryos is that they side-step ethical concerns among pro-life activists by obtaining pluripotent lines of undifferentiated cells without harm to a fetus or destruction of an embryo. These cells have demonstrated the ability to differentiate into a number of different cell-types, including brain, liver and bone cells [2-4].

It is possible, although difficult, to conserve the stem cells extracted from amniotic fluid. Amniotic fluid cells (AFCs) originate from fetal cells during pregnancy. When physicians conduct amniocentesis, they extract a small amount of amniotic fluid containing several types of fetal tissue and stem cells. The amniotic fluid that is aspirated in amniocentesis may be insufficient for clinical application, in which case physicians may be required to culture cells from the amniotic fluid. The success rate of AFC culture has dramatically increased over the years, so that culture failure currently occurs in no more than $0.5 \%$ of cases $[5,6]$.

AFC contains many of the stem cells required for forming organs and epithelial tissues in early stage fetal development. Furthermore, it is known that applying AFC to fetal wounds allows for scarless healing, unlike the adult scar healing process [7-9].

Due to this recent discovery, many researchers are putting their efforts into developing wound healing medications and many relevant pharmaceuticals. However, the exact mechanism of wound healing is still unknown $[5,10]$.

Therefore, in this study, the authors investigated the possibility of developing a wound healing medication using AFSCs and AFCs by conducting animal research using AFSC- and AFCderived medications to determine their effects on wound healing $[11,12]$.

\section{METHODS}

\section{Materials}

AFSCs and AFCs were obtained from genetic testing labs, collecting donations of the remaining cells leftover after amniotic fluid tests, with the patients' consent. The samples were collected from March to September of 2010. The obtained cells were closely examined in a MacConkey agar culture test and mycoplasma test to ensure the sterile condition of the cells, and infected cells were discarded. The obtained amniotic fluid was centrifuged to separate its tissue (stem) cells, divided into fractions, and cultured using T-flasks with cover glasses. After culturing an adequate amount of AFCs on the surface of the cover glass (DMEM low medium, Gibco-BRL, San Francisco, CA, USA), the cover glass was removed, the cultured AFCs were harvested use in other clinical trials, and the remaining T-flasks were returned to the biobank to culture more cells. Then, $5 \times 10^{4} \mathrm{~mL}$ of the cultured cells were seeded in each well of a well plate containing translucent porous polyester discs (Corepath Ltd., Daegu, Korea). The area of the disc was $710.28 \mathrm{~mm}^{2}$. These translucent porous polyester discs coated with cultured amniotic fluid cells were pulled out of the plate using a needle and each was put into a cryovial with culture media and cell freezing solution. The cryovials containing cultured cells were stored in deep freezers and then in liquefied nitrogen tanks in the biobank. The stored cells could be accessed conveniently by the researchers. This experiment utilized AFC (KBN-09) that was obtained from a genetic testing facility and AFSC (J43) obtained from the Joint Institute for Regenerative Medicine. In both instances they were cultured on porous polyester discs. The research and acquisition of the cells were authorized by the biomedical ethics committee and the cells were acquired from the biobank authorized by the Ministry of Health, Welfare and Family Affairs. The discs with the extracted stem cell were stored in the cryovial and then incubated in liquid nitrogen, which allowed convenient access to the AFC and AFSC discs whenever needed. After more than $80 \%$ of the colonies were cultured, the disc was put into a cryovial containing cell freezing solution. Then the cryovial was stored in an LN2 tank and thawed when the cells became necessary for the animal test. The thawed cells were then cultured to more than $100 \%$ of colony formation, and the cells were provided to the researchers when a cell membrane formed on the porous polyester disc.

Based on the selective application of cultured AFCs and AFSCs, the white rat population was divided into 4 different groups. A disc alone was applied on the wound of the rats in group A, a disc covered with collagen was applied on the wound of the rats in group B, a disc covered with collagen along with AFSCs was applied on the wound of the rats in group C, and group D received a treatment disc covered with collagen and processed with AFSCs (Collagen+AFC) (Fig. 1).

\section{Methods}

Four circular whole-layer skin incision wounds $2 \mathrm{~cm}$ in diameter were made on the back of 24 white rats, which were divided into 4 different experimental groups according to the treatment materials applied. The wounds were then observed until complete healing.

In order to induce anesthesia during the incision, $10 \mathrm{mg} / \mathrm{kg}$ of xylazine hydrogen chloride (Rompun, Bayer Korea, Seoul, Korea) and $100 \mathrm{mg} / \mathrm{kg}$ of ketamine hydrochloric acid $(\mathrm{HCl})$ (Ketamine, Huons, Seongnam, Korea) were mixed and injected into the abdominal cavity of the rats. After the rats had been anesthetized, they were prone positioned. Then the hair on the back of the rats was shaved, and, after sterilization using povi- 


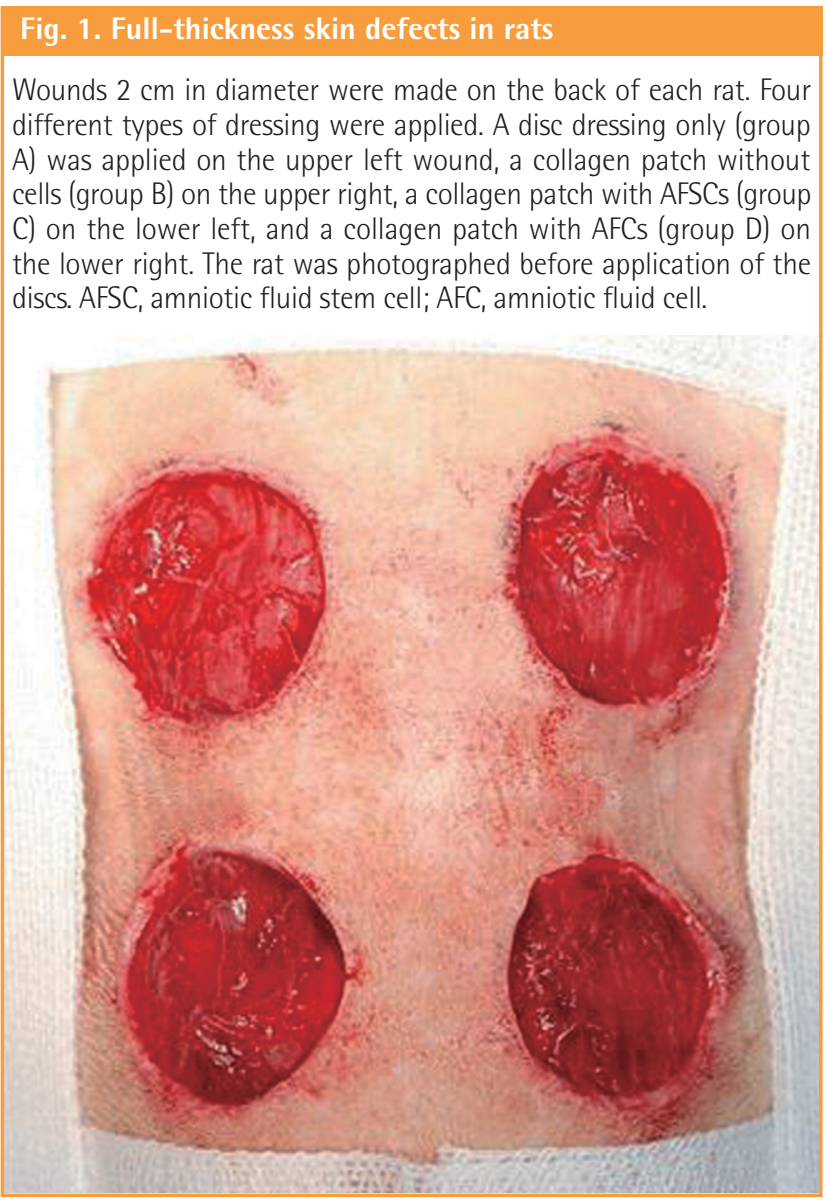

done-iodine and $70 \%$ alcohol, 4 places on the rat were marked with a circular stamp to form the 2-cm diameter circular wound margins. After making incisions with a No. 15 surgical blade, the muscular and subcutaneous layers were separated using a Metzenbaum scissors, and four whole-layer skin wounds $2 \mathrm{~cm}$ in diameter were made. After forming each wound, the different materials for group A, B, C, and D were applied in order, and the antibiotics were randomly given to minimize the effect on the wound site. In order to prevent the accidental loss of the medication, equidistantly punched Tegaderm (3M, St. Paul, MN, USA) was applied on top of the disc, and then sutured with blue nylon. The Tegaderm was not changed until the wound evaluation. Finally, the wounds were covered with gauze and lightly fixed using a 2 -inch elastic support bandage. The rats were observed until all of the wounds had completely healed. In general, all rats from all the groups underwent wound dressing once a day until the sixth day postoperatively, once every 2 days from day 6 to 14, and every 3 to 4 days after the 14th day. Because Tegaderm contains micropores, the exudate from the wounds passed through the Tegaderm and was absorbed into the gauze.

\section{Fig. 2. Method of measuring wound size}

Method for measuring changes in wound size. Wo, the initial wound area, $\mathrm{Wi}_{\mathrm{i}}$ the wound area on the day measured, $\mathrm{Ui}$, the area of unepithelialized granulation tissue on the day measured. Then we can suggest these fomula; Percentage of wound contraction $=\left(\right.$ Wo$\left._{0}-\mathrm{Wi}_{\mathrm{i}}\right) /$ Wo $\times 100$, percentage of wound epithelialization $=($ Wi-Ui $) /$ Wo $\times 100$ and percentage of wound healed $=($ Wo-Ui) $/$ Wo $\times 100$.
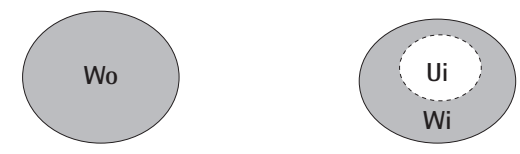

\section{Evaluation of the experimental results}

\section{Gross examination}

In order to conduct a gross evaluation of the 24 white rats, the researchers utilized Visitrak Grid (Smith and Nephew, Hull, UK) films and the Visitrak Digital (Smith and Nephew) wound area analysis system. The borders of the whole-layer wound right after the operation were traced on a sterile, transparent film, and the area was labeled "Wo." After a few days, granulomatous tissue had formed in the central area of the wound. The outer area that healed due to epithelialization was traced and labeled "Wi," and the actual area of granulomatous tissue was labeled "Ui." In 4 mice each, right after wound formation (Fig. 1), and on the fourth, sixth, tenth, 14th, 17th, and 21st days, digital photos were taken. Then, the wound was drawn on the Visitrak Grid film, and the whole wound area and epithelialized area were calculated separately. The percentages of wound contraction, wound healing, and wound epithelialization were calculated as the wound healing progressed (Fig. 2).

\section{Statistical evaluation}

The measured values of this study were evaluated by comparing the experimental groups using repeated-measures analysis of variance and Scheffe's test.

\section{Histological evaluation}

For the histological evaluation of the 24 rats, the wound tissue was divided into 2 equal parts. One part was for histological evaluation, the other one was for western blotting. The wound tissue was extracted from a section of the wound margin including the normal skin of four mice each on the fourth, sixth, tenth, 14th, 17th, and 21st days after the incision, and then fixed in neutral formaldehyde. The 4 mice were euthanized after the wound tissue extraction. Then, the fixed tissue was embedded with paraffin. The paraffin-embedded tissues were sectioned and dyed with both hematoxylin and eosin and Masson's trichrome reagent. Two slides were made from each of the rats' 
wounds. Under a light microscope, the inflammatory reaction of the wound site, vascularization, collagen fiber formation and arrangement, and the regeneration of the epithelia were observed.

\section{Western blot}

After the 4 mice were administered euthanasia on each evaluated day, in order to quantify transforming growth factor- $\beta$ and fibronectin levels, an indicator of inflammation in white rats, the extracted tissue samples were treated with $1 \mathrm{~mL}$ lysis buffer (50 mM N-2-hydroxyethylpiperazine-N'-2-eth-anesulfonic acid, $\mathrm{pH} 7.5,150 \mathrm{mM} \mathrm{NaCl}, 1 \mathrm{mM}$ ethylenedinitrolotetraacetic acid, $10 \%$ glycerol, $200 \mu \mathrm{M}$ sodium orthovanadate, $10 \mathrm{mM}$ sodium pyruvate, $50 \mathrm{mM}$ glycerol phosphate, and 1\% Triton X-100). The sample was homogenized using an electrical homogenizer. $2 \mu \mathrm{g} / \mathrm{mL}$ transforming growth factor- $\beta$ (TGF- $\beta$ ) and fibronectin antibodies were aliquoted to each well at a volume of $100 \mu \mathrm{L}$. This was followed by a 12-hour treatment at room temperature. Thus, the sample was coated with TGF- $\beta$ and fibronectin antibodies and then treated with phosphate buffer saline-T (5\% Tween 20 in PBS with 0.05\% NaN3, Sigma, St. Louis, MO, USA) at room temperature for an hour. This allowed the inhibition of non-specific antigen-antibody reactions. Total protein was extracted from each well, $40 \mu \mathrm{g}$ of which was administered to the sample. After making a standard curve by using a standard concentration of albumin, a quantitative analysis was performed at a density of $40 \mu \mathrm{g} / \mu \mathrm{L}$. After the reaction was performed at room temperature for 2 hours, the sample was rinsed. Biotin-conjugated antibody (anti-rat TGF- $\beta$ and fibronectin, Ab66043, Abcam, USA; $300 \mathrm{ng} / \mathrm{mL}$ ) was administered to each well at a volume of $100 \mu \mathrm{L}$. Then, the reaction was performed at room temperature for 2 hours. Streptavidin horseradish peroxidase was diluted at a ratio of 1:200 and administered to each well at a volume of $100 \mu \mathrm{L}$. Then the reaction was performed at room temperature for 20 minutes. Substrate solution (R\&D Systems Inc., Minneapolis, MN, USA) was added to each well at a volume of 100 $\mu \mathrm{L}$. The reaction was then performed at room temperature for 20 minutes. This was followed by the addition of $2 \mathrm{NH} 2 \mathrm{SO} 4$ to each well at a volume of $50 \mu \mathrm{L}$. After, the reaction was terminated, the optical density was measured at a wavelength of 450 $n m$, quantifying TGF- $\beta$ and fibronectin levels. Two blottings were performed for TGF- $\beta$ and fibronectin depending on the antibody.

\section{Flow cytometry analysis}

The specific surface antigens of AFSCs were characterized by flow cytometry analysis. The cultured cells were trypsinized and stained with phycoerythrin-conjugated mouse monoclonal antibodies (BD Pharmingen, San Diego, CA, USA) against CD29,
CD31, CD45, CD61, CD73, CD90, and CD105, and the results were analyzed using a flow cytometer (BD Biosciences, San Jose, CA, USA).

\section{RESULTS}

\section{Gross examination}

In the process of studying the serial pattern of the wound healing, the rats had to be euthanized as soon as they were analyzed due to specific pathogen free room limitations. The wounds had contracted and epithelialized as time passed, with each experimental group showing different appearances (Supplemental Fig. S1). As wound contraction and epithelialization progressed simultaneously, the non-epithelialized granulomatous tissue decreased, and wound healing was observed. No experimental group showed any signs of infection, and all groups had a small amount of fluid issuing from the wound up until the seventh day after the injury. The percentages of wound epithelialization and healing were higher in the experimental groups on the fourth, sixth, tenth, 14th, and 17th days after the injury $(\mathrm{P}<0.05)$, and the percentage of wound contraction was also higher in groups $\mathrm{C}$ and $\mathrm{D}$ on the fourth, sixth, tenth, 14th, and 17th days after the injury $(\mathrm{P}<0.05)$.

As a result, experimental groups $\mathrm{C}$ and $\mathrm{D}$ with AFSC extract and AFC extract, respectively, showed a significantly higher percentage of wound healing, contraction, and epithelialization than groups $\mathrm{A}$ and $\mathrm{B}$, which did not have AFSC extract or AFC extract $(\mathrm{P}<0.05)$.

In addition, group $\mathrm{D}$, with the injection of cultured AFC cells to the disc, showed a tendency toward a meeting a higher percentage of wound healing criteria compared to group $\mathrm{C}$ with

\section{Fig. 3. Mean wound contraction rate}

Based on the time progress over time of wound contraction of each group with the application of four different dressings. Experimental groups C and D with AFSC extract and AFC extract, respectively, showed a significantly higher percentage of wound contraction than groups $A$ and $B$, which did not have AFSC extract or AFC extract $(P<0.05$, values are significantly different from the control in 14th, 17th, 21st day according to ANOVA and Scheffe's test). AFSC, amniotic fluid stem cell; AFC, amniotic fluid cell.

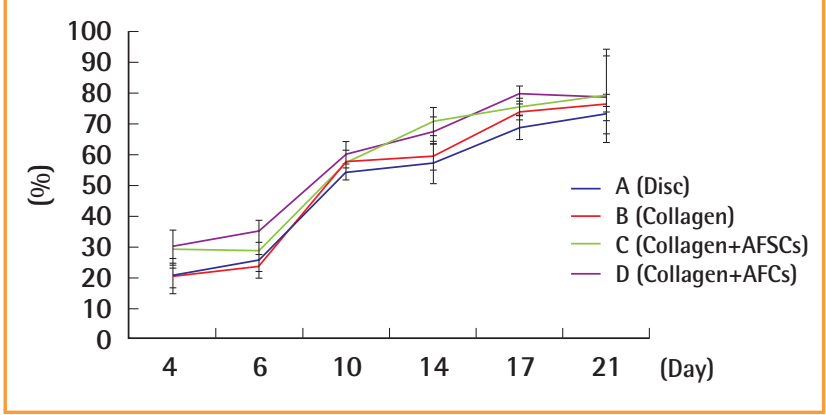




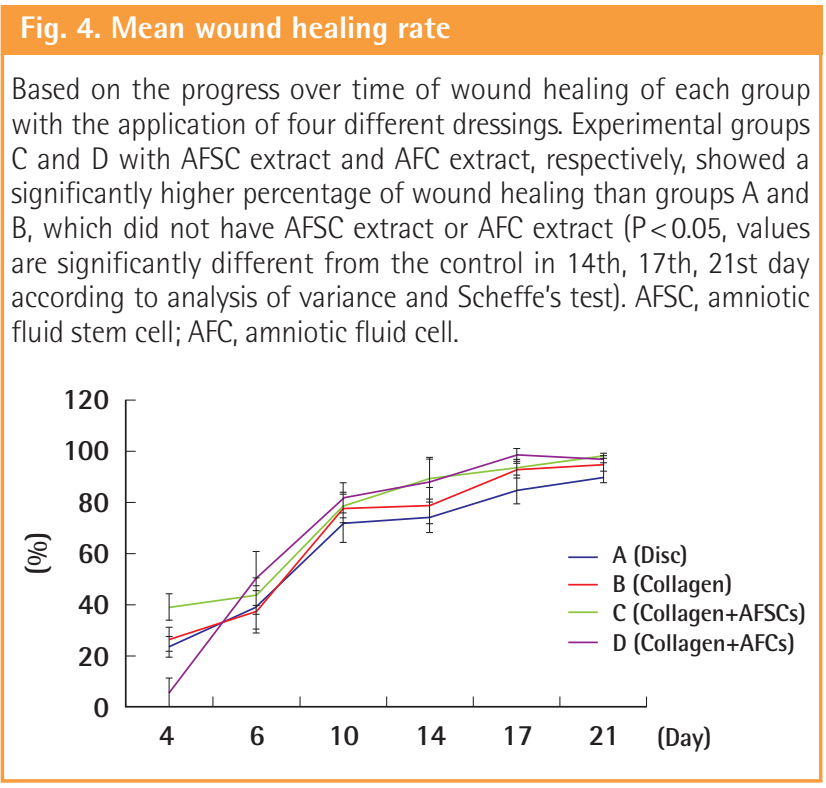

\section{Fig. 5. Mean percentage of wound epithelialization rate}

Based on the progress over time of wound epithelialization of each group with the application of four different dressings. Experimental groups C and D with AFSC extract and AFC extract, respectively, showed a significantly higher percentage of wound epithelialization than groups $A$ and $B$, which did not have AFSC extract or AFC extract. $P<0.05$, values are significantly different from the control in 14th, 17th, 21st day according to ANOVA and Scheffe's test. AFSC, amniotic fluid stem cell; AFC, amniotic fluid cell.

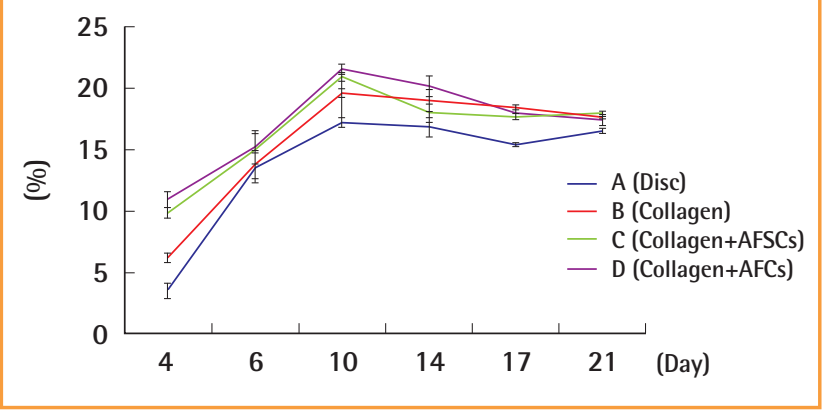

only AFSC injection, but this difference was not statistically significant (Figs. 3-5).

\section{Histological observation (Table 1)}

Up until the sixth day after the injury, polymorphonuclear cells and lymphocytes, indications of inflammation, were seen in every experimental group, with more inflammatory cells observed in groups $\mathrm{C}$ and $\mathrm{D}$ compared to the rest (Fig. 6). On the tenth day after the injury, all of the groups besides $\mathrm{A}$ and $\mathrm{B}$ showed increased angiogenesis. Also, more condensed and regular arrangements of collagen fibers were seen in groups $\mathrm{C}$ and $\mathrm{D} 14$ days after the wound was made (Fig. 7). When the wounds were completely healed, more condensed and organized collagen fibers were observed in groups $\mathrm{C}$ and $\mathrm{D}$, which, compared with

\begin{tabular}{|c|c|c|c|c|c|c|}
\hline \multirow[b]{2}{*}{ Date } & \multicolumn{2}{|c|}{ PWC } & \multicolumn{2}{|c|}{ PWE } & \multicolumn{2}{|c|}{ PWH } \\
\hline & $\begin{array}{l}\text { Aver- } \\
\text { age }\end{array}$ & $\begin{array}{l}\text { Standard } \\
\text { deviation }\end{array}$ & $\begin{array}{l}\text { Aver- } \\
\text { age }\end{array}$ & $\begin{array}{l}\text { Standard } \\
\text { deviation }\end{array}$ & $\begin{array}{l}\text { Aver- } \\
\text { age }\end{array}$ & $\begin{array}{l}\text { Standard } \\
\text { deviation }\end{array}$ \\
\hline \multicolumn{7}{|l|}{4 day } \\
\hline$A$ & 20.16 & 2.18 & 3.50 & 4.35 & 23.66 & 4.03 \\
\hline B & 20.36 & 3.02 & 6.21 & 6.04 & 26.57 & 4.63 \\
\hline C & 29.25 & 0.74 & 9.85 & 1.49 & 39.10 & 5.13 \\
\hline D & 30.08 & 1.09 & 10.94 & 2.17 & 41.02 & 5.54 \\
\hline \multicolumn{7}{|l|}{6 day } \\
\hline$A$ & 25.37 & 0.77 & 13.51 & 1.54 & 38.88 & 8.51 \\
\hline B & 23.52 & 3.59 & 13.78 & 7.18 & 37.30 & 8.17 \\
\hline C & 28.40 & 1.91 & 15.01 & 3.81 & 43.41 & 7.07 \\
\hline D & 34.91 & 2.91 & 15.20 & 5.82 & 50.11 & 10.53 \\
\hline \multicolumn{7}{|c|}{10 day } \\
\hline$A$ & 54.38 & 1.12 & 17.21 & 2.24 & 71.59 & 7.38 \\
\hline B & 57.79 & 1.16 & 19.57 & 2.32 & 77.36 & 5.39 \\
\hline C & 57.65 & 0.88 & 20.89 & 1.76 & 78.54 & 4.89 \\
\hline D & 60.07 & 0.75 & 21.52 & 1.49 & 81.59 & 5.68 \\
\hline \multicolumn{7}{|c|}{14 day } \\
\hline A & 57.20 & 1.06 & 16.85 & 2.13 & 74.05 & 6.01 \\
\hline B & 59.58 & 1.47 & 19.01 & 2.94 & 78.59 & 6.88 \\
\hline C & 70.81 & 0.46 & 17.95 & 0.92 & 88.76 & 7.62 \\
\hline $\mathrm{D}$ & 67.84 & 1.42 & 20.12 & 2.84 & 87.96 & 9.40 \\
\hline \multicolumn{7}{|c|}{17 day } \\
\hline$A$ & 68.81 & 0.72 & 15.42 & 0.72 & 84.23 & 4.89 \\
\hline B & 74.04 & 0.98 & 18.42 & 0.98 & 92.46 & 3.20 \\
\hline C & 75.56 & 0.74 & 17.68 & 0.74 & 93.24 & 3.18 \\
\hline$D$ & 79.97 & 0.63 & 18.01 & 0.63 & 97.98 & 2.72 \\
\hline \multicolumn{7}{|l|}{21 day } \\
\hline A & 73.44 & 15.06 & 16.23 & 30.11 & 89.67 & 2.40 \\
\hline B & 76.81 & 2.93 & 17.62 & 5.86 & 94.43 & 2.40 \\
\hline C & 79.56 & 3.09 & 17.95 & 6.18 & 97.51 & 1.31 \\
\hline D & 79.12 & 3.93 & 17.42 & 7.87 & 96.54 & 1.50 \\
\hline
\end{tabular}

PWC, percentage of wound contraction $=($ Wo-Wi $) /$ Wo $\times 100$; PWE, percentage of wound epithelialization $=(\mathrm{Wi}-\mathrm{Ui}) / \mathrm{Wo} \times 100$; $\mathrm{PWH}$, percentage of wound healed $=($ Wo-Ui $/$ Wo $\times 100$; Wo, the initial wound area; Wi, wound area on the day measured; $\mathrm{Ui}$, area of unepithelized granulation tissue on the day measured.

groups A and B, showed thicker, more mature, and more regenerated epithelium. On the 14th day after the injury, the results of an inflammatory cell count, which involved counting the number of inflammatory cells such as monocytes, fibroblasts, and giant cells, indicated that group A had $68.5 \pm 3.54$ cells, group B had $41.6 \pm 4.39$ cells, group $C$ had $37.8 \pm 3.76$ cells, and group D had $33.4 \pm 4.24$ cells, as observed under a light microscope at $400 \times$ magnification. Though these results were not meaningful statistically, they indicated that the experimental group with injections of AFSC and AFC extracts had fewer inflammatory cells at the last phase of wound healing compared to the control group without any injections.

\section{Western blot}

In a western blot test for TGF- $\beta$, the expression of the protein was higher in groups $\mathrm{C}$ and $\mathrm{D}$ than in the other groups. On the 


\section{Fig. 6. Inflammatory cell infiltration on the 6th postoperative day}

(A) Shows specimen of the group A which had a disc alone, (B) shows specimen of the group B which had a disc covered with collagen only, (C) shows specimen of the group $C$ which had a disc covered with collagen along with AFSCs and (D) shows specimen of the group D which had a disc covered with collagen and processed with AFCs. Note that mild inflammatory cell infiltration in group A and B, moderate inflammatory cell infiltration in group $C$ and profuse inflammatory cell infiltration in group D. H\&E, $\times 200$. AFSC, amniotic fluid stem cell; AFC, amniotic fluid cell.
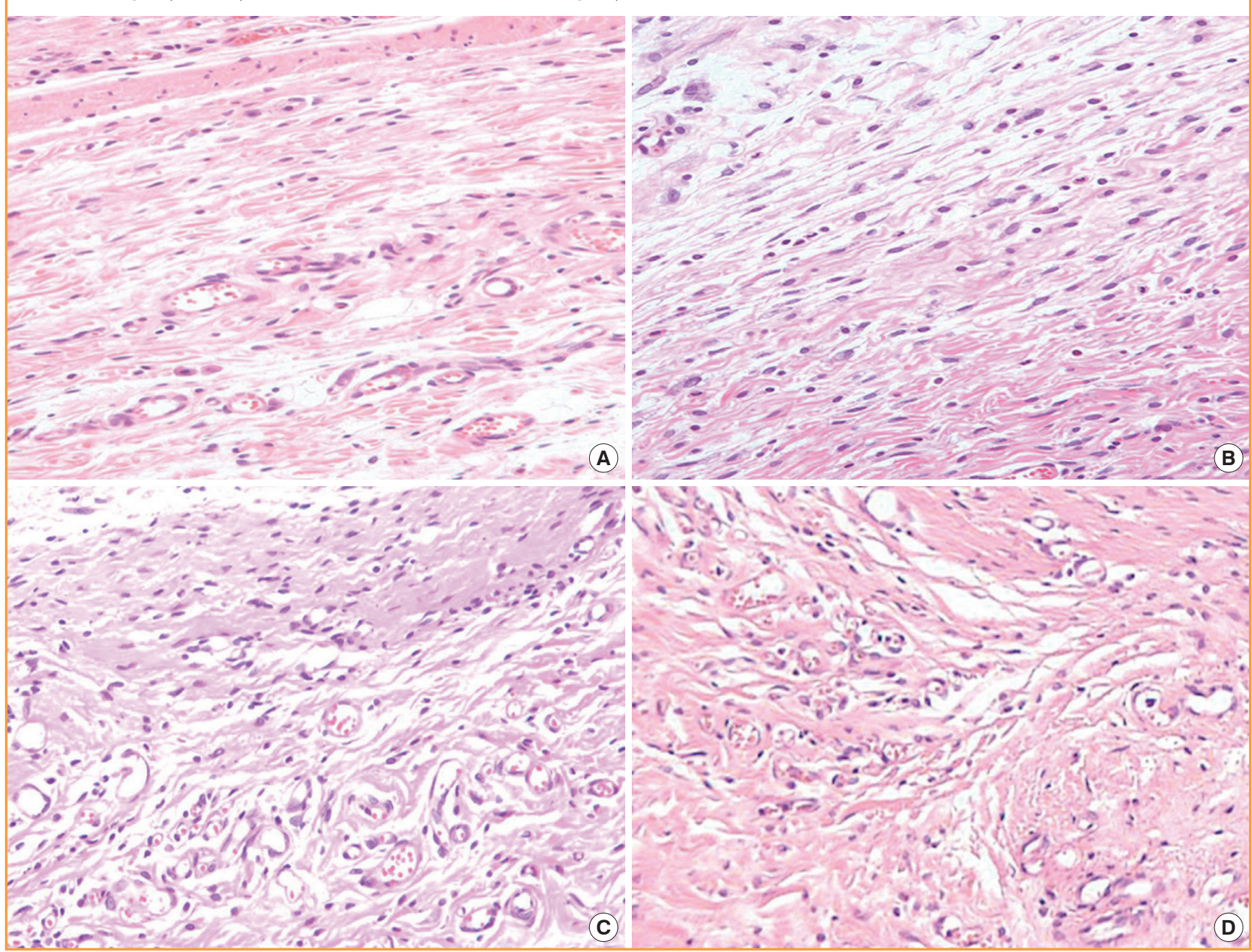

4th day after the injury, the expression of fibronectin was higher in group $\mathrm{D}$, but the results were not statistically significant. On the seventh day, the mid-phase of the wound healing, groups $C$ and D showed higher and much stronger expression of TGF- $\beta$. At the end phase of wound healing (day 18), no significant differences in protein expression among the groups were observed (Fig. 8). Image analysis was not performed because the results of the quantitative analysis acquired with ChemiDoc-It showed clear distinctions, grossly.

\section{Flow cytometry analysis}

Expressed surface antigens were detected by flow cytometry using mouse monoclonal antibodies. The antigens tested were CD29, CD73, CD90, CD105, CD31, CD45, and CD61. The AFSCs were positive for CD29, CD73, CD90, and CD105 and negative for CD31, CD45, and CD61.

\section{DISCUSSION}

Since the 1950s, amniocytes have been used for the prenatal diagnosis of various fetal malformations caused by genetic anomalies. They have been well established as diagnostic materials, but their cell origin and characteristics are not yet fully understood. When amniocytes were used for the diagnosis of genetic anomalies, they were attached to culture media, and only the cells that formed a colony were used. In the 1980s, studies on the various cells in amniotic fluid were recognized as necessary, so active studies have been conducted since then. Amniocytes are conveniently obtained during prenatal tests; the amount of cultured stem cells is large, their differentiation level is lower than that of 


\section{Fig. 7. Angiogenesis on the 14th postoperative day}

(A) Shows specimen of the group A which had a disc alone, (B) shows specimen of the group B which had a disc covered with collagen only, (C) shows specimen of the group $C$ which had a disc covered with collagen along with AFSCs and (D) shows specimen of the group D which had a disc covered with collagen and processed with AFSCs. Note that degree of angiogenesis and collagen fibers are more abundant in group C and D than group A and B. Masson's trichrome stain, $\times 200$. AFSC, amniotic fluid stem cell; AFC, amniotic fluid cell.
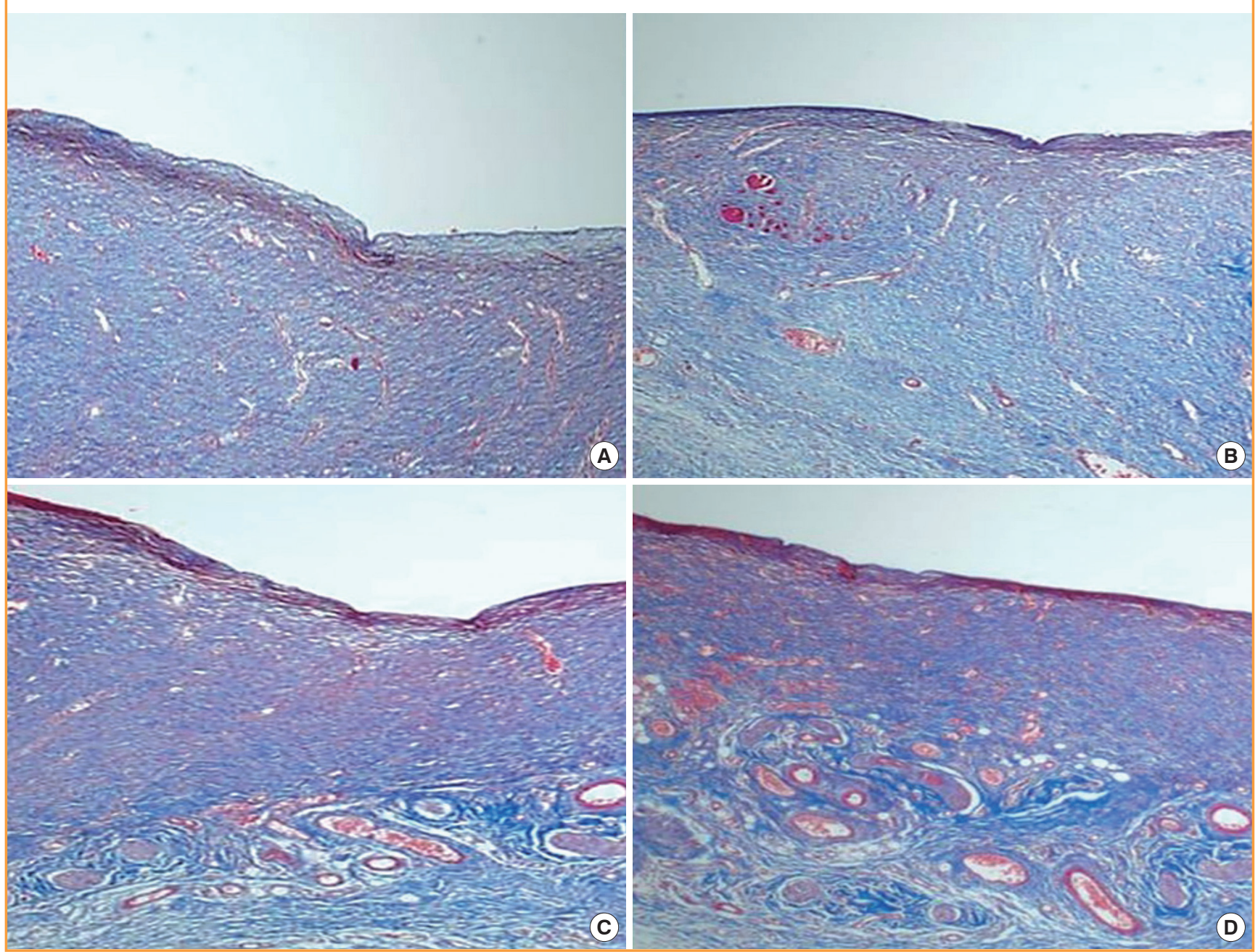

Fig. 8. Western blot of TGF- $\beta 1$, fibronectin, and $\beta$-actin in each group

TGF- $\beta 1$, fibronectin, and $\beta$-actin at1week and 3 weeks postoperatively. In a western blot test for TGF- $\beta$, the expression of the protein was higher in groups $C$ and $D$ than in the other groups. On the seventh day, the mid-phase of the wound healing, groups C and D showed higher and much stronger expression of TGF- $\beta$. At the end phase of wound healing (day 21), no significant differences in protein expression among the groups were observed. $A$, specimen of the group $A ; B$, specimen of the group $B ; C$, specimen of the group $C_{;} D_{1}$ specimen of the group $D ;$ TGF- $\beta$, transforming growth factor- $\beta$.

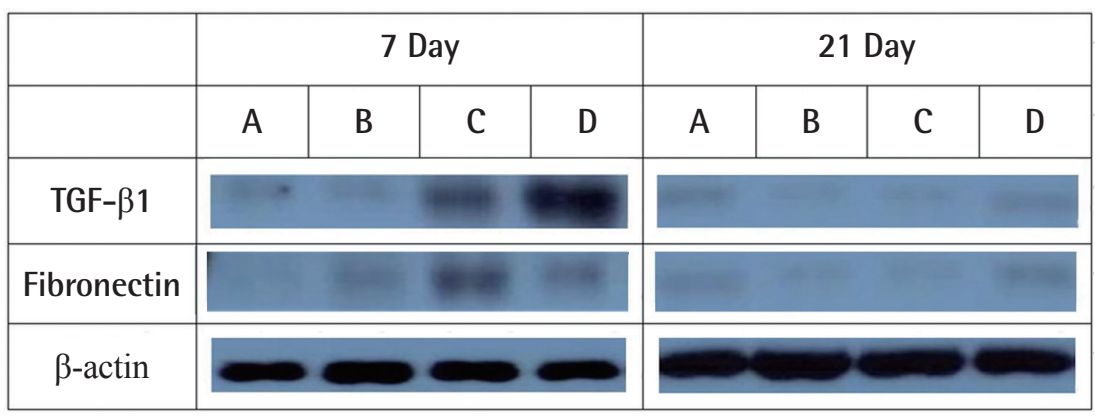

bone-marrow-derived stem cells, and no ethical questions associated with embryonic stem cells have been raised. In addition, they were reported to have shown better mesenchymal stem cell proliferation and colony formation abilities in amniotic fluid than in bone marrow. Accordingly, the possibility of in vitro differentiation of amniotic-fluid-derived mesenchymal stem cells, 
and the role of amniocytes as a useful source of mesenchymal stem cells that can be used for cell treatments have become important issues.

Various types of cells are mixed in the amniotic fluid, and the hormones secreted by the cells include human growth hormone, human-follicle-stimulating hormone, human luteinizing hormone, human chorionic gonadotropin, thyroid hormones, insulin, glucagon, testosterone, progesterone, estradiol, and cortisone. The wound-healing mechanisms of amniocytes were described in the literature on paracrine or autocrine effects. Cytokines are secreted upon completion of the stem cell engraftment in wound tissue due to the paracrine effect, and the treatment mechanisms of the stem cells, including apoptosis inhibition, angiogenesis promotion, substrate rearrangement, and aggregation of the circulating stem cell extracts can be observed accordingly. On the other hand, the injected stem cell extracts stimulate the stem cells around the wound site to differentiate into functional cells or to induce them to secrete cytokines. In this study, the effects and utility of the amniotic fluid stem cell extracts on wound healing were compared and analyzed. Unlike most of the previous studies that focused on AFSCs, experiments were conducted separately on the AFSC and AFC groups based on the assumption that there were synergic effects of the growth factors secreted by the surrounding tissues or cells for the active wound healing activities of the AFSCs. On day 4 postoperatively, the AFSC and AFC groups showed findings of inflammatory cell invasion, but on day 8 postoperatively, the number of inflammatory cells in these groups significantly decreased compared with the other groups. This may be because the various growth factors and cytokine secreted by the stem cells mediated the initiation of the inflammatory responses and had the chemotactic function of moving the surrounding inflammatory cells to the wound site, as well as due to the signal transduction function. On day 8 postoperatively, the most active angiogenesis findings were observed in the AFSC and AFC groups. This can be explained by the fact that the paracrine effect caused by stem cell engraftment in the wound tissue resulted in cytokine secretion, and accordingly, apoptosis inhibition, substrate rearrangement, and angiogenic effects occurred. On day 14 postoperatively, the formation of collagen fiber was observed in these groups. On day 21 postoperatively, significant epithelialization and regularly arranged collagen fibers were also observed in these groups. As shown on day 4 postoperatively, the AFSC and AFC groups reported inflammatory stages earlier than the other groups did, which meant they promoted wound healing and a shortened the healing period. As described earlier, the full-thickness skin wound was healed through wound shrinkage and epithelialization.
The AFSC and AFC groups showing the highest levels of the percentage of wound shrinkage and the wound epithelialization ratio, followed by the collagen patch and disc groups. To enhance wound healing efficiency using stem cells, the carrier that assists in cell engraftment and activities in the wound site is important. Novaes et al. [13] reported that stem cell seeding in the collagen matrix showed much better neovascularization than when other carriers were used. The collagen patch group showed statistically greater results than the disc group did because a collagen matrix support was made in addition to the carrier function of collagen. In this study, the AFSC and AFC groups showed a fast increase in the TGF-B and fibronectin levels at week 1 postoperatively compared with the control group. The origin of TGF-B and fibronectin expressed at that time was thought to have included the secretions of the injected umbilical-cord-blood-derived mesenchymal stem cells and of the surrounding tissues that were stimulated by the stem cells. AFCs are thought to play a more important role than AFSCs in early wound recovery. In the exudate, AFSC extracts were fluid. Therefore, if the exudates were removed, the substances that help the cells could also be removed. A slight amount of compression was applied to the wound and the gauze was changed every day in the early stage. The day after the early stage of the wound, the exudates were reduced and the gauze was changed every 2 or 3 days.

Upon gross examination, a considerable difference was observed between the control and experimental group, but no significant difference in P-value was confirmed. The AFC group had an AFSC:AFC ratio of only $10 \%$, and had $1 / 10$ th the amount of AFSCs compared with the AFSC group, but nevertheless showed similar results. These results were sufficiently encouraging. In conclusion, the AFSC and AFC groups showed less cell invasion, faster angiogenesis and fibroblast expression, and a larger amount of collagen fiber than did the other groups. As a result, the inflammatory stage of the wound healing process was accelerated, showing a fast cure rate and a shortened wound healing period. Therefore, they may be used as reliable wound treatment agents.

There were some limitations in this study. First, because 4 wounds were made in 1 rat, though we were able to reduce the selection bias, systemic effects such as the paracrine effect might have been a problem. However, contracture during wound healing can have effects on other nearby wounds. In order to make the distance between the wounds in a given rat consistently 2 $\mathrm{cm}$, we made the design on the X-ray film first, and drew the design of the rat's back based on the $\mathrm{X}$-ray film. 


\section{REFERENCES}

1. Dev K, Giri SK, Kumar A, et al. Derivation, characterization and differentiation of buffalo (Bubalus bubalis) amniotic fluid derived stem cells. Reprod Domest Anim 2012;47:704-11.

2. Jaramillo-Ferrada PA, Wolvetang EJ, Cooper-White JJ. Differential mesengenic potential and expression of stem cellfate modulators in mesenchymal stromal cells from humanterm placenta and bone marrow. J Cell Physiol 2012;227: 3234-42.

3. Tauzin $\mathrm{H}$, Humbert P, Viennet C, et al. Human amniotic membrane in the management of chronic venous leg ulcers. Ann Dermatol Venereol 2011;138:572-9.

4. Uberti MG, Lufkin AE, Pierpont YN, et al. Amnion-derived cellular cytokine solution promotes macrophage activity. Ann Plast Surg 2011;66:575-80.

5. Gosden CM. Amniotic fluid cell types and culture. Br Med Bull 1983;39:348-54.

6. Prusa AR, Marton E, Rosner M, et al. Oct-4-expressing cells in human amniotic fluid: a new source for stem cell research? Hum Reprod 2003; 18:1489-93.
7. Chung Y, Klimanskaya I, Becker S, et al. Human embryonic stem cell lines generated without embryo destruction. Cell Stem Cell 2008;2:113-7.

8. Kolambkar YM, Peister A, Soker S, et al. Chondrogenic differentiation of amniotic fluid-derived stem cells. J Mol Histol 2007;38:405-13.

9. Perin L, Giuliani S, Jin D, et al. Renal differentiation of amniotic fluid stem cells. Cell Prolif 2007;40:936-48.

10. Steele MW. Letter: Chromosome analysis of human amniotic-fluid cells. Lancet 1974;2:1210.

11. Rehni AK, Singh N, Jaggi AS, et al. Amniotic fluid derived stem cells ameliorate focal cerebral ischaemia-reperfusion injury induced behavioural deficits in mice. Behav Brain Res 2007;183:95-100.

12. Toda A, Okabe M, Yoshida T, et al. The potential of amniotic membrane/amnion-derived cells for regeneration of various tissues. J Pharmacol Sci 2007;105:215-28.

13. Novaes AB Jr, Marchesan JT, Macedo GO, et al. Effect of in vitro gingival fibroblast seeding on the in vivo incorporation of acellular dermal matrix allografts in dogs. J Periodontol 2007;78:296-303.

Supplemental Fig. S1. Serial gross photos of the rat's wound.

(A) Four days after application. (B) Six days after application. (C) Ten days after application.

(D) Fourteen days after application. (E) Seventeen days after application. (F) Twenty-one days after application.

Supplemental data can be found at: http://e-aps.org/src/sm/aps-40-496-s001.pdf 